\title{
What Is the Meaning of Extreme Phylogenetic Diversity? The Case of Phylogenetic Relict Species
}

\author{
Philippe Grandcolas and Steven A. Trewick
}

\begin{abstract}
A relict is a species that remains from a group largely extinct. It can be identified according both to a phylogenetic analysis and to a fossil record of extinction. Conserving a relict species will amount to conserve the unique representative of a particular phylogenetic group and its combination of potentially original characters, thus lots of phylogenetic diversity. However, the focus on these original characters, often seen as archaic or primitive, commonly brought erroneous ideas. Actually, relict species are not necessarily old within their group and they can show as much genetic diversity as any species. A phylogenetic relict species can be geographically or climatically restricted or not. Empirical studies have often shown that relicts are at particular risks of extinction. The term relict should not be used for putting a misleading emphasis on remnant or isolated populations. In conclusion, relict species are extreme cases of phylogenetic diversity, often endangered and with high symbolic value, of important value for conservation.
\end{abstract}

Keywords Geological extinction • Genetic diversity • Species age • Endemism • Remnant

\section{Introduction}

Why does phylogenetic diversity (or evolutionary distinctiveness) dramatically matter for biodiversity conservation? The answer to this question first posed by Vane-Wright et al. (1991) and Faith (1992) is often illustrated with examples of

\footnotetext{
P. Grandcolas $(\bowtie)$

Institut de Systématique, Evolution, Biodiversité, ISYEB - UMR 7205 CNRS MNHN

UPMC EPHE, Muséum National d'Histoire Naturelle, Sorbonne Universités,

45 rue Buffon, CP 50, 75005 Paris, France

e-mail:pg@mnhn.fr

S.A. Trewick

Ecology Group, Institute of Agriculture and Environment, Massey University,

Private Bag 11-222, Palmerston North, 4442 New Zealand

e-mail: s.trewick@massey.ac.nz 
emblematical and unique species. Such exemplar species that speak to everyone from layperson to scientist, include the Coelacanth fish, the Tuatara squamate, the Kiwi bird, the Platypus mammal, the Ginkgo tree, etc. All these species are said to be relict, because they represent groups that are mostly extinct (Grandcolas et al. 2014). The message is that these species should be cared for, because their extinction would cause a loss of information about distinct sections of life on Earth and their evolution. Generally, this powerful message is naively extended to characterize the place where these species are found, implying that the biota as a whole is a kind of Noah's ark, globally worthy of consideration for conservation biology (see for example, Gibbs 2006 for the case of New Zealand, or Thorne 1999 for Asia).

To our knowledge, everyone agrees with these views and even the most hardhearted companies or governments would difficulty take responsibility for destroying such emblematical "survivors". The public message in endorsing this destruction would be that they are the fools that spoil unique multimillion year antiques, even worse than to break a Vase de Soissons into thousands of pieces or to lacerate a delicate and wonderfully conserved Da Vinci painting. Even if very consensual, such emotive views about relicts and biodiversity conservation are still often presented informally, which prevent them to be fully scientific, i.e. theoretically justified, measurable and repeatable.

If then we try to set aside the emotional aspects of these views about relicts, what remains for conservation biology as a rational argument? Do relicts actually represent invaluable species for conservation purposes and why? Are they particularly exotic cases that do not account for most situations encountered by land managers or are they extreme cases of common situations? To answer these questions, we need to carefully define relicts with phylogenetic and paleontological tools. The properties of such characterizations need to be explored regarding the most important issues in conservation biology.

\section{What Then, Is a Relict Species?}

By definition, a relict is something that remains from an entity that has mostly disappeared (Merriam-Webster 2014; Lincoln et al. 1982). In evolutionary biology, a relict species remains of a group that is mainly extinct (Grandcolas et al. 2014; Fig. 1). The basis for this inference is the observation that a species stands alone on a long phylogenetic branch, by comparison with a larger sister-group, because of extinctions that occurred since the emergence of the stem group (Fig. 1). Formally, identifying a relict species requires comparison of sister-groups with different species numbers and characterization of extinction rates using phylogenetic tools on molecular trees (e.g., Ricklefs 2007; Rabosky 2006). This is the notion of phylogenetic relict species is distinct from geographical or environmental or climatic relict species where the relict state is defined according to spatial restriction supposedly arising from extinction of relatives in other parts of the geographical or ecological space (Habel and Assmann 2010; Hampe and Jump 2011). Here we will focus on 


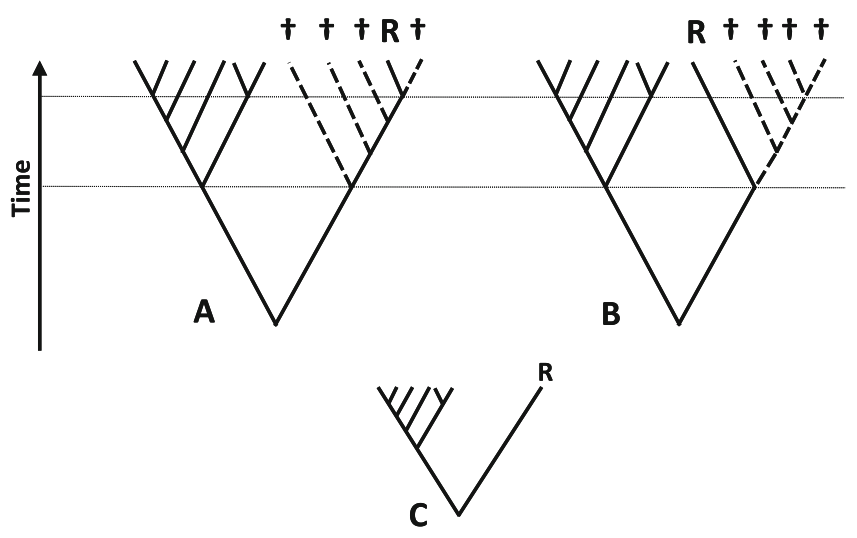

Fig. 1 Two different clades with a relict species " $R$ " remaining after species extinctions ( $\dagger$ ) in the right part of the clade. In the clade on the left (a), the relict is among the most recent species as indicated by the position on the time axis (dotted line) while in the clade on the right (b), the relict is among the most ancient species. It must be reminded that in most cases with lack of fossil record, the clade would look like the third one on the bottom of the figure (c), with the relict species alone on a long branch whose age is difficult to evaluate (c is like clade $\mathbf{a}$ or $\mathbf{b}$ )

the concept of phylogenetic relict species that is more relevant to phylogenetic diversity. We then briefly consider the concept of geographic or climatic relict species to pinpoint when it has some added value for conservation purposes. These geographical or climatic relict populations could be better called "remnants" in order to avoid confusion with relict species.

When dealing with presumptive relicts in a tree, it is first necessary to check that such long phylogenetic branches are not artifacts generated by problems of tree construction. The most common problem of this kind is long-branch attraction when the analysis of molecular data tends to draw together long branches because of sampling deficiency or fast-evolving molecular markers (Bergsten 2005). A species may be placed onto such an artificially long branch when the inference procedure does not find closely related species, either because they are lacking in the taxon sample of the analysis or because selected DNA sequences have diverged much faster, erasing the information of relatedness. Such naked branches frequently become artificially long because they fall to the base of the reconstructed tree. This problem can look trivial but could occur more and more frequently when phylogenetic analyses are performed at community level within the framework of metagenomics: local and community-focused sampling will not necessarily ensure a reasonable taxonomic coverage and could generate more artifacts than traditional and taxonomy-focused phylogenetic studies.

Second, two theoretical cases have been distinguished among phylogenetic relict species: species that survived an extinction event depleting their group and species belonging to groups that never speciated much (Table 1). Simpson (1944) named them numerical and phylogenetic relicts, respectively. Actually, real situations are inevitably a mix of these two theoretical cases; even in small clades, the relict 
Table 1 Theoretical characteristics of the different kinds of relicts with reference to the evolutionary process involved, the criterion of characterization and the origin of the deep and long branch. Any real situation is actually a combination of the two first theoretical cases and of the third one to different extents. The third case, the geographical or climatic relict, is not necessarily a relict sensu stricto but merely a remnant, if not positioned on a deep long branch

\begin{tabular}{l|l|l|l}
\hline Kinds of relict & $\begin{array}{l}\text { Evolutionary } \\
\text { process }\end{array}$ & Criterion & Deep long branch \\
\hline "Numerical" relict & Extinction & Fossil record & Built on extinction \\
\hline "Phylogenetic" relict & Low speciation & Molecular rate & Built on time \\
\hline $\begin{array}{l}\text { Geographical or climatic } \\
\text { "relict" }\end{array}$ & Area restriction & $\begin{array}{l}\text { Fossil record or } \\
\text { distribution }\end{array}$ & Not necessarily \\
\hline
\end{tabular}

remains from a larger group because extinction rates are never totally zero. Estimating the degree to which long branches have been generated by extinction or by evolutionary stasis requires a combination of data from different research fields. A long molecular branch, whatever its origin, will be most often diagnosed as the result of extinction by methods of "lineage through time" plots (Ricklefs 2007; Quental and Marshall 2010). Paleontological evidence is needed in addition to molecular trees. If a group is known to have been much more speciose in the past, it strongly indicates that the relict actually remains from a much larger and extinct group. From this criterion comes the famous term "living fossil" coined by Darwin (1876) himself: these "like fossils, connect to a certain extent orders at present widely sundered in the natural scale." Living fossil is however a misleading term because it could lead to the belief that relicts remain globally similar to related fossil taxa through some type of generalized evolutionary stasis (e.g., Eldredge 1987; Eldredge et al. 2005; Parsons 2005). Evolutionary stasis is exceedingly difficult to diagnose since we can always expect to unveil differentiation when we observe more characters in the so-called living fossil and therefore to discard the stasis hypothesis. Actually, none of the classic relicts has ever been found similar to early fossil relatives after closer investigation, therefore refuting the idea of a generalized evolutionary stasis. For example, the venom in Platypus is not archaic but totally original, neither squamate nor mammal-type (O'Brien 2008), the coelacanth fish is originally modern in its reproduction mode, being ovoviviparous (Casane and Laurenti 2013). The term "panchronic" (e.g., Janvier 2007) has also been used in this way with the same wrong assumption that relict taxa did not evolve.

Operationally, identifying relict most frequently relies on the phylogenetic criterion because many groups have scanty paleontological records. To what extent this is helpful and meaningful, given the limitations of "lineage through time" plots (Quental and Marshall 2010; Crisp and Cook 2009; Dowle et al. 2013) is unclear. The results obtained in macroevolutionary analyses are always reconstructions from the past, based on incomplete samples and await confirmation by more studies; proposal of a relict species requires a dedicated search for auxiliary evidence for extinction, including an improved fossil record (Grandcolas et al. 2014). 
Given this generally accepted definition (e.g., Simpson 1944; Brooks and McLennan 1991), a relict is a species that will show a high phylogenetic diversity score according to any metric (Rodrigues et al. 2005). This is a species that is on a relatively long branch that separated from the remainder of the clade under consideration (i.e. the relict and its sister-group). Therefore, both the position of the species in the phylogenetic topology and the amount of divergence are remarkable. Conserving a relict will contribute to preservation of a species with unique phylogenetic information and with many distinctive (say autapomorphic) characters.

\section{What a Relict Species Is Not?}

Most of the problems with the concept of relicts come from associated concepts that are not formally part of this definition. Because they are survivors, relicts are often misleadingly considered as "missing links", "living ancestors" or "primitive or basal taxa." These three last notions are based on a still common misunderstanding of most basic issues in phylogenetics and evolutionary biology (Crisp and Cook 2005). They are based on the fallacious generalization to the whole species of phylogenetic results obtained on very small and biased samples of characters, suggesting that a species would be globally "intermediate" or "primitive." In a classic case of circular reasoning, a few remarkably "primitive" characters observed in a living species are traditionally considered to have originated very deep in the Tree of Life and are misleadingly considered diagnostic of the globally primitive state of this species and vice versa. The assumption is that searching for other characters would necessarily show that they are also in a primitive state. This assumption is naive because there are no reasons to assume that billions of phenotypic or genomic characters in the same species have all been subject to a global evolutionary stasis. In addition, this assumption has never been empirically met when such species are studied further.

For example, Mastotermes darwiniensis, the sister group to all other termites is present today only in Australia but found worldwide in the fossil record. It has profoundly archaic wing venation, egg laying and female genitalia, but it also shows an amazingly derived and multiflagellate spermatozoid (Legendre et al. 2008; Abe et al. 2000). The small tree Amborella trichopoda that is endemic to New Caledonia is considered to be the sister group to all flowering plants (Soltis et al. 2002). It has very often been used as a proxy for the ancestral state of many phenotypic traits (e.g., Friedman and Ryerson 2009). However, its mitochondrial genome is amazingly modern and composite, resulting from many horizontal transfers from diverse organisms (Bergthorsson et al. 2004; Rice et al. 2013). There is no organism where all characters are primitive or intermediate like a living ancestor. According to the principles of phylogenetics, it is well recognized that an ancestor with all characters plesiomorphic is therefore by nature paraphyletic and could not be characterized or identified by even only one apomorphy (Nelson 1970; Engelmann and Wiley 1977). In addition, and from a semantic point of view, the term "basal" is nonsensical since 
two sister-groups are the same rank, one cannot be basal to the other (Krell and Cranston 2004).

An interesting and neglected characteristic of a relict having survived extinctions is that it is not necessarily a "deep-branching" or "old" species (Fig. 1a); the species could have branched either recently or deeply within a group of which most members of which are already gone (Grandcolas et al. 2014). A molecular phylogenetic study, based only on extant taxa, will not be able to distinguish the age of the species from lineage age (Fig. 1c), unless it permits the discovery of genetic diversity within the crown group species (i.e. several species that were previously confused or several haplotypes within the same species) which will allow the distinction from the stem group. This possibility has been recently illustrated by exemplary studies bearing on famous relict taxa: the coelacanth fishes (Inoue et al. 2005), the cycad plants (Nagalingum et al. 2011), and the gymnosperms as a whole (Crisp and Cook 2011). In these cases, the extant species have been dated as recently differentiated in very old clades that mostly went extinct long ago. Therefore, conserving a relict does not conserve an ancestor or a particular stage of an old evolutionary history but a unique combination of character states representing a larger but mainly extinct group.

\section{Are Relict Species Evolutionarily Frozen?}

We mentioned that taking relicts as living ancestors is an obviously fallacious inference, but this point of view has also been formulated in less exaggerated and misleading terms. For example, relicts have often been considered to have lower evolutionary rates, being in someway evolutionarily frozen (e.g., Amemiya et al. 2010), which would explain why they did not speciate giving rise to a large group. Parsons (2005) defended the idea that those relicts that live in very specialized and stable niches (e.g., hypersaline biota) would not be subjected to many biotic interactions, preventing any further adaptive change. The same kind of reasoning has been applied to other supposedly narrow niches (Ricklefs 2005), from caves (Gibert and Deharveng 2002; Assmann et al. 2010), deep-sea vents (Van Dover et al. 2002) and oceanic islands (Cronk 1992). The rationale is that the relict is subjected to little diversifying selection in a stable niche, so there is little anagenetic change in the lineage. Darwin (1876: 83-84) himself expressed this for what he called living fossils: "they have endured to the present day, from having inhabited a confined area, and from having been exposed to less varied, and therefore less severe, competition." Adopting this view, some biologists have questioned the evolutionary value and potential of relicts (e.g., Erwin 1991; Myers and Knoll 2001; Mace and Purvis 2008). Some also doubted the extent to which phylogenetic diversity is an all-purpose criterion to measure the importance of species (Winter et al. 2013): phylogenetic diversity may indicate which species are evolutionarily unique, but does it indicate also which species have evolutionary potential and ability to evolve and to adapt further in a changing world, or both? What use is there for conserving a relict informing about past evolution if it represents the living dead, unable to adapt and soon extinct when facing the next environmental changes? 
If all relicts really proved to be frozen or genetically depauperate and unable to evolve, their conservational value would be actually highly decreased. However, we should suspect that these wide generalizations may not always be correct and a brief literature review readily shows that they do not correspond to many real situations. For example, several case studies have shown that coelacanth fishes (Holder et al. 1999; Casane and Laurenti 2013), and also horseshoe crabs (Avise et al. 1994) have a polymorphic genetic structure, even in spite of their globally conserved genome. Recent studies also showed in some relict species, the tuataras or the Cercidiphyllum trees, two other emblematical relict species, the same pattern of mutational and retention of population genetic diversity as in other species (Hay et al. 2008; Qi et al. 2012). More generally, Casane and Laurenti (2013) also warned not to use raw population genetic diversity as a proxy for documenting evolutionary rate or stasis, as it depends on the population size or on the selection forces that could hide high mutation rate. The computation of evolutionary rates also strongly depends on the scale of sampling through generations.

Conserving a relict species is therefore not just a way to save high organismic diversity and it is not at odds with retaining potential for future evolution. Recent empirical and theoretical studies have pointed out that conserving a phylogenetically diverse set of species could be a bet-hedging strategy that allows retention of species with most diverse characteristics of any kind, including evolutionary potential in the short term, i.e. adaptiveness (Faith 1992 chapter 3; Forest et al. 2007; Steel et al. 2007; Davies et al. 2008; Davies and Cadotte 2011; Fjeldså et al. 2012; Lean and Maclaurin chapter "The Value of Phylogenetic Diversity"). Actually, this potential should better be measured and evaluated in each case and not assumed from a priori conceptions of evolutionary stasis. Predicting the evolutionary potential of species on the long term (potential for speciating and radiating) is another issue, actually not feasible from any of their present characteristics (Barraclough and Davies 2005; Winter et al. 2013). We should however remember that the evolutionary record of hundreds of millions years told us many cases of strong diversifications in groups that were first strongly depleted (e.g., Neoaves, Eutherian mammals, etc.) Even if we cannot predict the future of a present relict species in thousands or millions of years, we should at least consider that it is actually not necessarily closed in terms of potential for surviving and diversifying, given what we know from the past histories of other several groups.

\section{Is There a Geographical or a Climatic Component to the Notion of Relictness?}

In the earliest papers on the subject, species were considered relicts according to an inexplicit mixture of several components: taxonomic (now phylogenetic), climatic (e.g., the famous glacial relicts) and geographic (Darwin 1876; Simpson 1944; Darlington 1957; Holmquist 1962; Cronk 1992). All were considered because some species show relict features under each of these criteria, being both phylogenetic and geographic relicts. More recently, Parsons (2005) has drawn some interesting 
inferences about the reasons why relicts (that he also called living fossils) can be geographically limited or not. A typical and often cited case is the tree Gingko biloba, found today only in a region of China and an amazing phylogenetic relict of the large group of Gingkoales well known from the Cretaceous fossil record (Zhou 2009). This coincidence of criteria is however not always the case and some conspicuous phylogenetic relicts are quite widely distributed, including the horseshoe crab (e.g., Selander et al. 1970) and some tropical bird species (Fjeldså 1994). It appears then that the geographic or environmental criterion is secondary. Sometimes it fits, sometimes it does not, and all relict species need first to be documented on a phylogenetic basis. A "remnant" species strongly restricted geographically (typically isolated or peripheral) is not necessarily a relict that is isolated by extinction of its closest relatives. Phylogenetic or genetic studies could infer other less expected scenarios. The related group of the remnant could have been affected by both extinction and increase of neighboring distributions or the remnant may have originated after a dispersal event from a large distribution source (Fig. 2).

The traditional view of geographical restriction still expressed by various authors also considers the territories harboring one or several famous relicts as antique refuges (Gibbs 2006; Heads 2009). Generally, this biogeographic reasoning is quite circular, justifying the presence of relicts by the old geological age of the deep basement and considering it as a Noah's Ark (without consideration for more recent and decisive paleogeographic events such as land submersion, major climatic changes, etc.) and vice versa, without searching for independent biological evidence (Waters
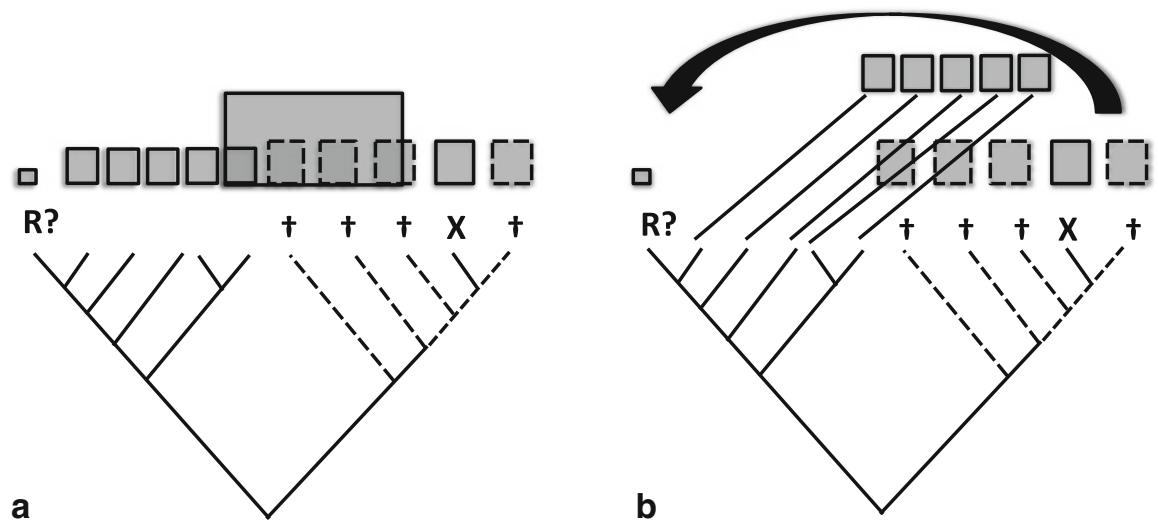

Fig. 2 Two theoretical examples showing how the assumption that a geographically restricted or peripheral species is a relict can be falsified. These examples should be examined first with respect to distribution areas only (upper part of the figure), and then with consideration for the phylogenetic tree and extinctions events ( $\dagger$ and spotted lines, lower part). In both cases, $\mathrm{R}$ ? was falsely believed to be a relict on a geographical basis alone (most peripheral and smallest distribution area) while the actual relict $X$ was not identified as such. In the first case (a), the species $X$ was not detected as a relict in the lineage because the distribution area of a neighboring species increased since the extinction of relatives. In the second case (b), the species $\mathrm{R}$ ? was the most peripheral and isolated one because of a dispersal event from the zone where all the other species of the group were located including the species that went extinct 
and Craw 2006). Actually, the fact that a relict remains from a larger group that is mainly extinct is a specific circumstance that makes difficult any inference of local permanence because relatives have disappeared and cannot therefore inform about the evolution of the distribution (Grandcolas et al. 2014).

Being a phylogenetic and a geographical relict at the same time is a frequent case and it brings even more concern for conservation. The relict species is then not only evolutionarily unique but also particularly vulnerable in case of local disturbance because of its limitation to a reduced area. As emphasized by Rodrigues et al. (2005), if this relict occurs in a small area that is not species-rich, it is even more potentially endangered because conservation actions will not be undertaken for other reasons.

There is however a recent trend to define as relicts some narrowly distributed or isolated populations when the species distribution is fragmented, even if the evolutionary status or phylogenetic position of these populations is either not known or presumptively not "deep-branching" and even if there is no evidence that this isolation was caused by the extinction of some related populations (Habel and Assmann 2010; Hampe and Jump 2011). Perhaps, dispersal caused the fragmented distribution (Fig. 2)? Population and conservation biologists wish to point out that such fragmented, isolated or remnant populations are worthy of further investigation or consideration for conservation (e.g., Laurance and Bierregaard 1997). In our opinion, this trend is confusing and brings polysemy within the term "relict." Surviving extinctions as evidenced by phylogeny or the fossil record for whole species is not the same as having a decreasing or a fragmented distribution area for some populations within a species even if it involves some genetic differentiation (see even Watson 2002, who applies "relict" to the species present in forest fragments prior to fragmentation). Such short-lived population changes are likely frequent and dynamic, as shown by paleoenvironmental studies. One could assume that geographically relict populations are phylogenetically relict species in statu nascendi, but there is not (yet) evidence for that. We should be patient and wait for a few thousands of years at least before making our judgement... This is the reason why we proposed that the term relict should only be employed for phylogenetic relict species only. The so-called climatic or geographical relicts should then be better called "remnants" and qualifying the target category (population, forest fragment, etc.), for example, a climatic remnant population or a geographic remnant population (see Eriksson 2000 for a clarification and their possible functional importance).

From the point of view of conservation biology, this clarification is clearly needed and it permits distinction between two different cases. A phylogenetic and possibly geographical relict species must be considered for conservation since it contributes to organismic phylogenetic diversity and is possibly geographically or ecologically vulnerable. A climatic remnant population may just increase local diversity by the presence of one more species and, more significantly, may contribute to inform about interesting historical or ecological processes of distributional changes (Hampe and Jump 2011). The remnant population is neither necessarily deeply rooted into the history of the lineage nor remaining from a larger set. This 
has to be eventually documented. Other cases of small distribution areas (for example, newly established populations of expanding species) are still another case, neither relict species nor remnant populations, but population isolates.

\section{Relictness: A Relative Notion and the Need for Formal Analyses}

The term relict is generally employed either for emblematic taxa or for well-defined situations where taxonomic, phylogenetic and paleontological characterizations are established from previous studies and publications. This definition generally embodies the relict species, its very large sister-group, the paleontological record and the geographic restriction if any. For example, the relict Amborella trichopoda is the sister-group of all other flowering plants and it is only found in New Caledonia (Soltis et al. 2002). But relictness is not a particular state of a character that can be distinguished unambiguously from other and different states. Like most other classlevel characterizations such as rarity, specialization or endemism (e.g., Rabinowitz 1981; Futuyma and Moreno 1988; Anderson 1994), relictness is a relative and composite situation that needs to be established by comparison, and in every case by phylogenetic comparison. Strictly speaking, we should not say Amborella trichopoda is "a relict" but Amborella trichopoda is "a relict species for flowering plants." This comparison is based on topology and branch lengths that depend on the taxon and character samples used to build the tree. This way, within flowering plants, there are many groups that stand isolated on long branches and could be called relicts, such as Welwitschia, Ephedra, etc., actually hundred of species among hundreds of thousands of plant lineages (for examples see Jacobson and Lester 2003; Dilcher et al. 2005). As it is set by comparison between sister-groups within a phylogenetic tree, characterization as a relict will depend on the taxon sample used in that tree. For non-phylogeneticists, this could sound like a limitation of this notion that makes it less useful. Actually, a statement of relictness needs to be based on a formal phylogenetic analysis conducted on a given set of taxa. Depending on the tree obtained, a gap analysis can show that one or several branches have exceptional lengths and originate deep in the tree. These branches and their terminal taxa can be named relict taxa. This is required to implement the phylogenetic diversity criterion for conservation, characterizing the extreme case of relicts at the same time.

\section{Relicts and Ecosystem Functioning}

Macroevolutionary studies of this type might appear to be far removed from the real nowaday's world where ecosystems must function and populations must be viable to be conserved. Actually, historical and functional views are not opposed or 
disconnected (Brooks and McLennan 1991; Grandcolas 1998). Current research (e.g., Elias et al. 2013) in the framework of community phylogenetics (Ricklefs and Latham 1992; Webb et al. 2002) shows that trophic webs have a phylogenetic structure. Phylogenetic niche conservatism mitigated by exploitative competition means that related species can have similar resource use (Cadotte et al. 2008; but see Mouquet et al. 2012). In this theoretical framework, a relict is then expected to exploit a unique niche, a prediction consistent with some of the adaptive explanations cited above (e.g., Parsons 2005), that relicts can be highly specialized (but inconsistent with relicts as generalists).

Therefore, maximizing phylogenetic diversity for conservation can be expected to select for species whose resource use is unique (Srivastava et al. 2012; Winter et al. 2013). In cases where relicts are found in a very stable and specialized habitat harboring small communities, this original resource use might implicate a key ecosystem service (e.g., Gibert and Deharveng 2002). At the extreme, structuring ecological communities by conserving species on the basis of phylogenetic diversity should select against loss of function in communities, by retaining species with lower niche overlap even if ecological redundancy is decreased.

\section{Relict Species and Present Extinction Risks}

Relict species are therefore extreme cases of phylogenetic diversity and conserving them is of outstanding interest. In addition, they are not the living dead some people see them, which would have no viable populations or be unable to evolve or diversify again, as pictured by some people. In terms of conservation biology, however, we should not only consider whether they are valuable in themselves for conservation but also if they are at higher present extinction risk because of global change and human activities. As detailed by Yessoufou and Davies (chapter "Reconsidering the Loss of Evolutionary History: How Does Non-random Extinction Prune the Tree-of-Life?"), statistical studies suggest that species-poor, monotypic families, small genera and old groups in mammals, birds and plants - in other words, potentially relicts - are all more prone to extinction (Gaston and Blackburn 1997; Russell et al. 1998; Purvis et al. 2000; Meijaard et al. 2008; Vamosi and Wilson 2008; López-Pujol and Ren 2010). The causes of this situation probably lie in heritable phenotypic traits associated with long branches in these groups (Grandcolas et al. 2011). Even if these studies are biased by focusing on a few well-known groups (mammals, birds and plants) and by using proxies as red lists or meta-analyses for estimating extinction risks, they undoubtedly showed that present extinction could potentially have pernicious effects that were not suspected a priori (Nee and May 1997), by destroying proportionally more evolutionarily unique species. These results require more attention and future analyses should turn toward identifying the phenotypic characters that increase present vulnerability. It should not be assumed however that modern and past extinction risks are the same. The reasoning can be inverted; relicts are successful survivors from past geological times that could resist 
any present global change, unless global change is fundamentally different from previous extinction crises.

Relicts are not only worthwhile to conserve by themselves because they are evolutionarily unique. They can also be at higher present extinction risks for phenotypic reasons that remain to explore in every case. Independently from any phenotypic effect, geographical or climatic relictness and therefore a small distribution area can also be a source of vulnerability in itself.

\section{Relict Species and Conservation Biology: A Final Appraisal}

Relict species, even if not all famous and rooted in very deep histories such as Platypus or Gingko, have been used as a powerful metaphor for explaining the use of phylogenetic diversity in the framework of conservation biology. We have seen that this is appropriate since relicts do represent an extreme case of phylogenetic diversity (Rodrigues et al. 2005). Relicts help understanding that some species can have a unique and decisive historical value, beyond strictly numerical considerations involving species counts or metrics measurements. From this qualitative point of view, phylogenetic diversity has already been given a lot of consideration (contra Winter et al. 2013; but see Rosauer and Mooers 2013). A growing body of research also shows that relict species are probably at higher present risk of extinction, which qualifies them for conservation planning from both perspectives.

Unfortunately, the metaphor has also been a vehicle for several misconceptions, that relicts are also living ancestors, basal taxa, or missing links. Even if these most outdated ideas are extirpated, there remains the tendency of some modern conservation biologists to erroneously conceive relicts as old species with poor evolutionary potential.

One important message of this chapter is therefore to explain why this later conception cannot be generalized or taken as true a priori. When dealing with relicts and phylogenetic diversity in general, it must always be recalled that the present diversity is the result of the balance between past speciation and past extinction. This way, relicts remain from larger groups partly extinct. The consequence is that any computation of their age will be strongly biased if the past occurrence of extinct species is not taken into account. The age of the relict species could be equated naively with the age of the crown group and the base of the branch, when it might actually be quite recent. In addition, the evolutionary rate of the relict lineage should be measured and not just assumed to be generally low by focusing on a minority of emblematical phenotypic characters that remained stable over long time periods.

Conserving organismic diversity requires consideration for "the whole real guts of evolution - which is, how do you come to have horses, and tigers, and things" (Waddington (1967) quoted by Eldredge and Cracraft (1980)). But such a historical view is not at odds with conserving a functional world and a world still keeping some evolutionary potential. There are not two different worlds, the one with the 
animals of the zoo and the other with balanced trophic relationships and resilience to global environmental changes.

The other confusion to avoid is that relicts are not simply geographic or ecological remnants. Part of a population can remain in a habitat patch after ecosystem fragmentation without being evolutionarily relict. Using the term "relict" to put emphasis on any isolate or remnant biological entity is unhelpful and confusing.

The metaphor of relicts is not only useful to explain the scientific importance of phylogenetic diversity but also has added political value for the development of public conservation planning. Because of its emblematical value, a relict is potentially a flag species whose presence in a location could help promote conservation. Because of their importance, the position and the characteristics of such relict taxa must be even more accurately specified. We should focus on knowing better to conserve better.

Acknowledgements We gratefully thank Jon Fjeldså, Mike Crisp, Dan Faith and Roseli Pellens for their comments on the manuscript, which greatly helped clarifying the ideas presented here. We also took benefit of reading other chapters of the book that provided rich reviews about various aspects of phylogenetic diversity and that allowed more maturation than just cross-referencing. Finally, we are also grateful to many people who commented on previous versions of our thoughts about relicts in other contexts.

Open Access This chapter is distributed under the terms of the Creative Commons AttributionNoncommercial 2.5 License (http://creativecommons.org/licenses/by-nc/2.5/) which permits any noncommercial use, distribution, and reproduction in any medium, provided the original author(s) and source are credited.

The images or other third party material in this chapter are included in the work's Creative Commons license, unless indicated otherwise in the credit line; if such material is not included in the work's Creative Commons license and the respective action is not permitted by statutory regulation, users will need to obtain permission from the license holder to duplicate, adapt or reproduce the material.

\section{References}

Abe T, Bignell DE, Higashi M (eds) (2000) Termites: evolution, sociality, symbioses, ecology. Kluwer Academic Publishers, Dordrecht

Amemiya CT, Powers TP, Prohaska SJ, Grimwood J, Schmutz J, Dickson M, Miyake T, Schoenborn MA, Myers RM, Ruddle FH, Stadler PF (2010) Complete HOX cluster characterization of the coelacanth provides further evidence for slow evolution of its genome. Proc Natl Acad Sci U S A 107:3622-3627

Anderson S (1994) Area and endemism. Q Rev Biol 69:451-471

Assmann T, Casale A, Drees C, Habel JC, Matern A, Schuldt A (2010) Review: the dark side of relict species biology: cave animals as ancient lineages. In: Habel JC, Assmann T (eds) Relict species: phylogeography and conservation biology. Springer, Berlin, pp 91-103

Avise JC, Nelson WS, Sugita H (1994) A speciational history of "living fossils": molecular evolutionary patterns in horseshoe crabs. Evolution 48:1986-2001 
Barraclough TG, Davies TJ (2005) Predicting future speciation. In: Purvis A, Gittleman JL, Brooks T (eds) Phylogeny and conservation. Cambridge University Press, Cambridge, pp 400-418

Bergsten J (2005) A review of long-branch attraction. Cladistics 21:163-193

Bergthorsson U, Richardson AO, Young GJ, Goertzen LR, Palmer JD (2004) Massive horizontal transfer of mitochondrial genes from divers land plant donors to the basal angiosperm Amborella. Proc Natl Acad Sci U S A 101:17747-17752

Brooks DR, McLennan DA (1991) Phylogeny, ecology, and behavior: a research program in comparative biology. The University of Chicago Press, Chicago

Cadotte MW, Cardinale BJ, Oakley TH (2008) Evolutionary history and the effect of biodiversity on plant productivity. Proc Natl Acad Sci 105:17012-17017

Casane D, Laurenti P (2013) Why coelacanths are not 'living fossils'. BioEssays 35:332-338

Crisp MD, Cook LG (2005) Do early branching lineages signify ancestral traits? Trends Ecol Evol 20:122-128

Crisp MD, Cook LG (2009) Explosive radiation or cryptic mass extinction? Interpreting signatures in molecular phylogenies. Evolution 63:2257-2265

Crisp MD, Cook LG (2011) Cenozoic extinctions account for the low diversity of extant gymnosperms compared with angiosperms. New Phytol 192(4):997-1009

Cronk QCB (1992) Relict floras of Atlantic islands: patterns assessed. Biol J Linn Soc 46:91-103

Darlington PJ (1957) Zoogeography: the geographical distribution of animals. Wiley, New York

Darwin CR (1876) The origin of species by means of natural selection, or the preservation of favoured races in the struggle for life, 6th edn. John Murray, London, with additions and corrections

Davies TJ, Cadotte MW (2011) Quantifying biodiversity: does it matter what we measure? In: Zachos FE, Habel JC (eds) Biodiversity hotspots. Springer, pp 43-60

Davies TJ, Fritz SA, Grenyer R, Orme CDL, Bielby J, Bininda-Emonds ORP, Cardillo M, Jones KE, Gittleman JL, Mace G, Purvis A (2008) Phylogenetic trees and the future of mammalian biodiversity. Proc Natl Acad Sci U S A 105:11556-11563

Dilcher DL, Bernardes-De-Oliveira ME, Pons D, Lott TA (2005) Welwitschiaceae from the lower cretaceous of northeastern Brazil. Am J Bot 92:1294-1310

Dowle EJ, Morgan-Richards M, Trewick SA (2013) Molecular evolution and the latitudinal biodiversity gradient. Heredity $110: 501-510$

Eldredge N (1987) Part 5. Living fossils. Introduction. In: Eldredge N (ed) The natural history reader in evolution. Columbia University Press, New York, pp 137-139

Eldredge N, Cracraft J (1980) Phylogenetic patterns and the evolutionary process: method and theory in comparative biology. Columbia University Press, New York

Eldredge N, Thompson JN, Brakefield PM, Gavrilets S, Jablonski D, Jackson JBC, Lenski RE, Lieberman BS, McPeek MA, Miller W (2005) The dynamics of evolutionary stasis. Paleobiology 31:133-145

Elias M, Fontaine C, van Veen FJ (2013) Evolutionary history and ecological processes shape a local multilevel antagonistic network. Curr Biol 23:1355-1359

Engelmann GF, Wiley EO (1977) The place of ancestor-descendant relationships in phylogeny reconstruction. Syst Zool 26:1-11

Eriksson O (2000) Functional roles of remnant plant populations in communities and ecosystems. Global Ecol Biogeogr 9:443-449

Erwin TL (1991) An evolutionary basis for conservation strategies. Science 253:750-752

Faith DP (1992) Conservation evaluation and phylogenetic diversity. Biol Conserv 61(1):1-10

Fjeldså J (1994) Geographical patterns for relict and young species of birds in Africa and South America and implications for conservation priorities. Biodivers Conserv 3:207-226

Fjeldså J, Bowie RCK, Rahbek C (2012) The role of mountain ranges in the diversification of birds. Annu Rev Ecol Evol Syst 43:249-265

Forest F, Grenyer R, Rouget M, Davies TJ, Cowling RM, Faith DP, Balmford A, Manning JC, Proches S, van der Bank M, Reeves G, Hedderson TAJ, Savolainen V (2007) Preserving the evolutionary potential of floras in biodiversity hotspots. Nature 445:757-760 
Friedman WE, Ryerson KC (2009) Reconstructing the ancestral female gametophyte of angiosperms: insights from Amborella and other ancient lineages of flowering plants. Am J Bot 96:129-143

Futuyma DJ, Moreno (1988) The evolution of ecological specialization. Annu Rev Ecol Syst 19:207-233

Gaston K, Blackburn T (1997) Evolutionary age and risk of extinction in the global avifauna. Evol Ecol 11:557-565

Gibbs G (2006) Ghosts of Gondwana. The history of life in New Zealand. Craig Potton Publishing, Nelson

Gibert J, Deharveng L (2002) Subterranean ecosystems: a truncated functional biodiversity. Bioscience 52:473-481

Grandcolas P (1998) Phylogenetic analysis and the study of community structure. Oikos 82:397-400

Grandcolas P, Nattier R, Legendre F, Pellens R (2011) Mapping extrinsic traits such as extinction risks or modelled bioclimatic niches on phylogenies: does it make sense at all? Cladistics 27:181-185

Grandcolas P, Nattier R, Trewick SA (2014) Relict species: a relict concept? Trends Ecol Evol 29:655-663

Habel JC, Assmann T (eds) (2010) Relict species: phylogeography and conservation biology. Springer, Berlin

Hampe A, Jump AS (2011) Climate relicts: past, present, future. Annu Rev Ecol Evol Syst 42:313-333

Hay JM, Subramanian S, Millar CD, Mohandesan E, Lambert DM (2008) Rapid molecular evolution in a living fossil. Trends Genet 24:106-109

Heads M (2009) Globally basal centres of endemism: the Tasman-coral sea region (south-west Pacific), Latin America and Madagascar/South Africa. Biol J Linn Soc 96:222-245

Holder MT, Erdmann MV, Wilcox TP, Caldwell RL, Hillis DM (1999) Two living species of coelacanths? Proc Natl Acad Sci U S A 96:12616-12620

Holmquist C (1962) The relict concept - is it a merely zoogeographical conception? Oikos 13:262-292

Inoue JG, Miya M, Venkatesh B, Nishida M (2005) The mitochondrial genome of Indonesian coelacanth Latimeria menadoensis (Sarcopterygii: Coelacanthiformes) and divergence time estimation between the two coelacanths. Gene 349:227-235

Jacobson KM, Lester E (2003) A first assessment of genetic variation in Welwitschia mirabilis hook. J Hered 94:212-217

Janvier P (2007) Living primitive fishes and fishes from deep time. In: David J, McKenzie APF, Colin JB (eds) Fish physiology, vol 26. Academic Press, San Diego, pp 1-51

Krell FT, Cranston PS (2004) Which side of the tree is more basal? Syst Entomol 29:279-281

Laurance WF, Bierregaard RO (eds) (1997) Tropical forest remnants. Ecology, management, and conservation of fragmented communities. Chicago University Press, Chicago

Legendre F, Whiting MF, Bordereau C, Cancello EM, Evans TA, Grandcolas P (2008) The phylogeny of termites (Dictyoptera: Isoptera) based on mitochondrial and nuclear genes: implications for and the evolution of the worker and pseudergate castes, and foraging behaviors. Mol Phylogenet Evol 48:615-627

Lincoln RJ, Boxshall GA, Clark PF (1982) A dictionary of ecology, evolution and systematics. Cambridge University Press, Cambridge

López-Pujol J, Ren MX (2010) China: a hot spot of relict plant taxa. In: Rescigno V, Maletta S (eds) Biodiversity hotspots. Nova Publishers, Hauppauge, pp 123-137

Mace GM, Purvis A (2008) Evolutionary biology and practical conservation: bridging a widening gap. Mol Ecol 17:9-19

Meijaard E, Sheil D, Marshall AJ, Nasi R (2008) Phylogenetic age is positively correlated with sensitivity to timber harvest in Bornean mammals. Biotropica 40:76-85

Merriam-Webster.com. Retrieved 3 Mar 2014, from http://www.merriam-webster.com/dictionary/ relict 
Mouquet N, Devictor V, Meynard CN, Munoz F, Bersier L-F, Chave J, Couteron P, Dalecky A, Fontaine C, Gravel D, Hardy OJ, Jabot F, Lavergne S, Leibold M, Mouillot D, Münkemüller T, Pavoine S, Prinzing A, Rodrigues ASL, Rohr RP, Thébault E, Thuiller W (2012) Ecophylogenetics: advances and perspectives. Biol Rev 87(4):769-785

Myers N, Knoll AH (2001) The biotic crisis and the future of evolution. Proc Natl Acad Sci U S A 98(10):5389-5392

Nagalingum NS, Marshall CR, Quental TB, Rai HS, Little DP, Mathews S (2011) Recent synchronous radiation of a living fossil. Science 334:796-799

Nee S, May RM (1997) Extinction and the loss of evolutionary history. Science 278:692-694

Nelson GJ (1970) Outline of a theory of comparative biology. Syst Zool 19:373-384

O’Brien SJ (2008) The Platypus genome unraveled. Cell 133:953-955

Parsons PA (2005) Environments and evolution: interactions between stress, resource inadequacy and energetic efficiency. Biol Rev 80:589-610

Purvis A, Agapow PM, Gittleman JL, Mace GM (2000) Nonrandom extinction and the loss of evolutionary history. Science 288:328-330

Qi X-S, Chen C, Comes HP, Sakaguchi S, Liu Y-H, Tanaka N, Sakio H, Qiu Y-X (2012) Molecular data and ecological niche modelling reveal a highly dynamic evolutionary history of the East Asian tertiary relict Cercidiphyllum (Cercidiphyllaceae). New Phytol 196:617-630

Quental TB, Marshall CR (2010) Diversity dynamics: molecular phylogenies need the fossil record. Trends Ecol Evol 25:434-441

Rabinowitz D (1981) Seven forms of rarity. In: Synge H (ed) The biological aspects of rare plant conservation. Wiley, Chichester, pp 205-217

Rabosky DL (2006) Likelihood methods for detecting temporal shifts in diversification rates. Evolution 60:1152-1164

Rice DW, Alverson AJ, Richardson AO, Young GJ, Sanchez-Puerta MV, Munzinger J, Barry K, Boore JL, Zhang Y, dePamphilis CW, Knox EB, Palmer JD (2013) Horizontal transfer of entire genomes via mitochondrial fusion in the angiosperm Amborella. Science 342:1468-1473

Ricklefs RE (2005) Small clades at the periphery of passerine morphological space. Am Nat 165:651-659

Ricklefs RE (2007) Estimating diversification rates from phylogenetic information. Trends Ecol Evol 22:601-610

Ricklefs RE, Latham RE (1992) Intercontinental correlation of geographical ranges suggests stasis in ecological traits of relict genera of temperate perennial herbs. Am Nat 139:1305-1321

Rodrigues AS, Brooks TM, Gaston KJ (2005) Integrating phylogenetic diversity in the selection of priority areas for conservation: does it make a difference? In: Purvis A, Gittleman JL, Brooks T (eds) Phylogeny and conservation. Cambridge University Press, Cambridge, pp 101-119

Rosauer DF, Mooers AO (2013) Nurturing the use of evolutionary diversity in nature conservation. Trends Ecol Evol 28(6):322-323

Russell GJ, Brooks TM, McKinney MM, Anderson CG (1998) Present and future taxonomic selectivity in bird and mammal extinctions. Conserv Biol 12:1365-1376

Selander RK, Yang SY, Lewontin RC, Johnson WE (1970) Genetic variation in Horseshoe Crab (Limulus-Polyphemus), a phylogenetic relic. Evolution 24:402-414

Simpson GG (1944) Tempo and mode in evolution. Columbia University Press, New York

Soltis DE, Soltis PS, Albert VA, Oppenheimer DG, dePamphilis CW, Ma H, Frohlich MW, Theissen G, Grp FGPR (2002) Missing links: the genetic architecture of flower and floral diversification. Trends Plant Sci 7:22-31

Srivastava DS, Cadotte MW, MacDonald AAM, Marushia RG, Mirotchnick N (2012) Phylogenetic diversity and the functioning of ecosystems. Ecol Lett 15:637-648

Steel M, Mimoto A, Mooers AO (2007) Hedging our bets: the expected contribution of species to future phylogenetic diversity. Evol Bioinforma 3:237-244

Thorne RF (1999) Eastern Asia as a living museum for archaic angiosperms and other seed plants. Taiwania 44:413-422 
Vamosi JC, Wilson JRU (2008) Nonrandom extinction leads to elevated loss of angiosperm evolutionary history. Ecol Lett 11:1047-1053

Van Dover CL, German CR, Speer KG, Parson LM, Vrijenhoek RC (2002) Marine biology - evolution and biogeography of deep-sea vent and seep invertebrates. Science 295:1253-1257

Vane-Wright RI, Humphries CJ, Williams PH (1991) What to protect? Systematics and the agony of choice. Biol Conserv 55:235-254

Waddington CH (1967) Comment made during discussion of paper by Dr. Eden. In: Moorehead PS, Kaplan MM (eds) Mathematical challenges to the Neo-Darwinian interpretation of evolution. Wistar Institute Press, Philadelphia, p 14

Waters JM, Craw D (2006) Goodbye Gondwana? New Zealand biogeography geology, and the problem of circularity. Syst Biol 55:351-356

Watson DM (2002) A conceptual framework for studying species composition in fragments, islands and other patchy ecosystems. J Biogeogr 29:823-834

Webb CO, Ackerly DD, McPeek MA, Donoghue MJ (2002) Phylogenies and community ecology. Annu Rev Ecol Syst 33:475-505

Winter M, Devictor V, Schweiger O (2013) Phylogenetic diversity and nature conservation: where are we? Trends Ecol Evol 28:199-204

Zhou ZY (2009) An overview of fossil Ginkgoales. Palaeoworld 18:1-22 